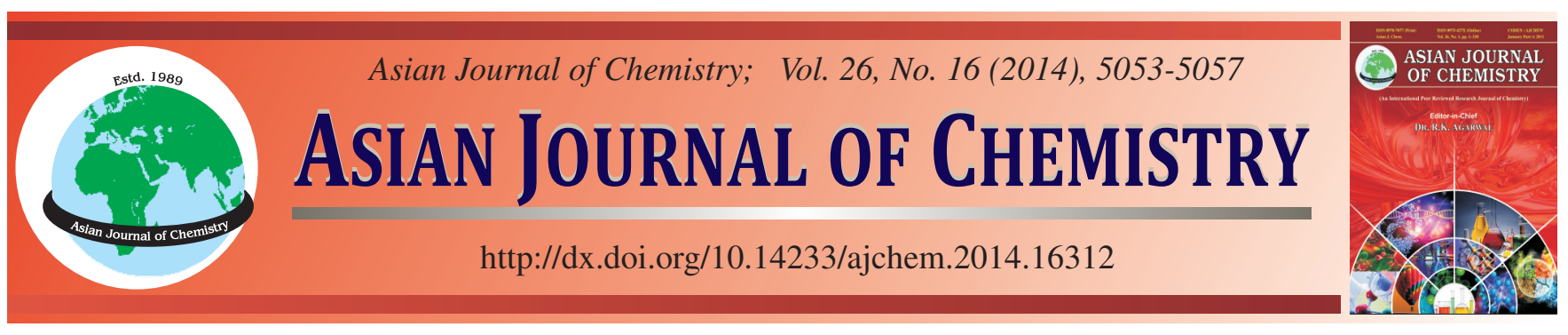

\title{
Determination of Eucomic Acid in Chinese Hawthorn Fruit and Products by Gas Chromatography-Mass Spectrometry
}

Zhe Gao, Rong-Fang Wang, Xiao-Hu Kang, Ai-Xia Qin, Ya-Nan Jia, Tong-Sen He, Yu-Lei Pan and Tong Cui*

College of Food Science and Technology, Agricultural University of Hebei, Baoding 071001, Hebei Province, P.R. China

*Corresponding author: Fax: +86 312 7528195; Tel: +86 312 7528427; E-mail: cuitong98@aliyun.com

\begin{abstract}
An analytical method for determination of eucomic acid in Chinese hawthorn fruit and its products by gas chromatography-mass spectrometry (GC-MS) was developed. The sample was extracted by ethanol, esterificated with sulphuric acid-methanol solution and then extracted with dichloromethane. The final analysis was performed by GC-MS using the fragment ions $m / z, 107$ under selected ion monitoring (SIM) for the content of eucomic acid. External standard method was used for quantification. Under optimum conditions, there was a good linearity within the range of $2-500 \mu \mathrm{g} / \mathrm{g}$. The limit of detection was $0.35 \mu \mathrm{g} / \mathrm{g}$, the recoveries were in the range $87-102 \%$, the relative standard deviation (RSD) was 3.1-5.6\%. This method was applied to determine the eucomic acid in hawthorn fruit and its products. The content is between $5.1-255 \mu \mathrm{g} / \mathrm{g}$.
\end{abstract}

Keywords: Eucomic acid, Eucomic acid 1,4-dimethyl ester, GC-MS, Crataegus pinnatifida, Flavor component.

\section{INTRODUCTION}

Hawthorn have been widely used as medicinal and food materials in China and in certain European countries ${ }^{1}$. Chinese hawthorn is one of the most popular fruits in north China, because of its special flavor and beneficial health effects in treating digestive ailments, dyspnea, kidney stones and cardiovascular disorders ${ }^{2}$. The flavor components of Chinese hawthorn fruit were analyzed by GC-MS and a total of 90 compounds have been detected ${ }^{3}$. However, limited data on its characteristic flavor compounds have been reported. In our previous research of polyphenol in hawthorn fruit extracts, we found the existence of eucomic acid (eucomic acid, Fig. 1), which was the characteristic fragrance of hawthorn fruit. Due to the fact that it rarely exists in other fruits, eucomic acid is a potential index for a quality assessment of hawthorn fruit and products.

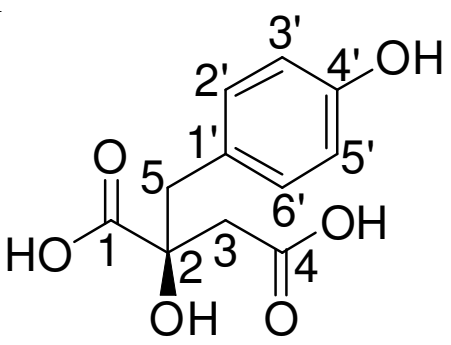

Fig. 1. Chemical structure of eucomic acid
Eucomic acid, a secondary metabolite in plants, was first isolated from the bulbs of Eucomis punctata L' Hér. (Liliaceae) and later identified as (2R)-2-( $p$-hydroxybenzyl) malic acid by Heller and Tamm ${ }^{4}$. It was also found in Lycoris radiata ${ }^{5}$, Cattleya trianaei ${ }^{6}$, Opuntia vulgaris Mill ${ }^{7}$, Crotalaria sessiliflora $\mathrm{L}^{8}$, Cactus stems (Opuntia spp. $)^{9}$, Opuntia dillenii ${ }^{10}$, Encyclia michuacana ${ }^{11}$, Prichly Pear (Opuntia ficus-indica (L) Mill.) ${ }^{12}$ and Turpinia arguta Seem ${ }^{13}$. Recently, eucomic acid was identified as an endogenous metabolite in leaf movement in the model organism, Lotus japonicus ${ }^{14}$. According to the research on Vanda teres ${ }^{15}$, eucomic acid contributed to stimulate respiratory functions in keratinocytes by increasing cytochrome $\mathrm{c}$ oxidase activity and/or expression and is therefore a potential new natural ingredient for antiaging preparations to remedy age-related disorders. However, quantitative analysis for eucomic acid has not been reported. Therefore, this paper aims to develop a stable and reliable GC-MS analytical method for the quantification of eucomic acid.

\section{EXPERIMENTAL}

The Sephadex LH-20 was purchased from Sigma Chemical Co. (Pharmacia, Sweden). Deuterium dimethyl sulfoxide $\left(\mathrm{CD}_{3} \mathrm{SOCD}_{3}\right)$, tetramethylsilane (TMS) and deuterated acetone $\left(\mathrm{CD}_{3} \mathrm{COCD}_{3}\right)$ were purchased from Beijing Boya Dabei Technology Development Co. (Beijing, China). The methanol and acetonitrile used for the HPLC mobile phase were HPLC grade. The water was double distilled water. Dichloromethane, 
4-oxo-pentanoic acid, malic acid, citric acid, isocitric acid were analytical grade. The solution of sulphuric acid-methanol was $12: 100(\mathrm{v} / \mathrm{v})$.

The hawthorn fruits (Crataegus pinnatifida Bge. var. major N.E.Br.) were purchased from markets in Baoding, Hebei, China and the cultivar was Dajinxing. Hawthorn juice (I and II), Hawthorn jam, Hawthorn jelly and Hawthorn soup were purchased from the market.

GC-MS analysis was performed on an Agilent 7890A gas chromatograph (Agilent Technologies, Shanghai, China), 5975C Mass Selective Detector (Agilent Technologies, Santa Clara, CA, USA) and 7683B autosampler (Agilent Technologies, Little Falls, DE, USA), fitted with a HP-5MS fused silica capillary GC column $(30 \mathrm{~m} \times 0.25 \mathrm{~mm}$ i.d., $0.25 \mu \mathrm{m}$ film thickness). Analytical high-performance liquid chromatography (HPLC) systems (Agilent Technologies) fitted with a Hypersil BDS C18 column $(250 \mathrm{~mm} \times 4.6 \mathrm{~mm}$ i.d., $5 \mu \mathrm{m})$. Preparative HPLC systems (Beijing Chuangxin Tongheng Science and Tecnology Co., Ltd, Beijing, China) fitted with a SinoChrom ODS-BP C18 column $(300 \mathrm{~mm} \times 20 \mathrm{~mm}$ i.d, 10 $\mu \mathrm{m})$. LC-MS analysis was performed using an Agilent 1100 Series LC/MSD Trap System (California, USA) and equipped with an ESI source. NMR spectra were measured on a Bruker Avnce III 600 MHz (Bruker Biospin Crop, Ettlingen, Germany).

Extraction and purification of eucomic acid: A $14 \mathrm{~kg}$ (FW) fruit sample was cut into pieces and extracted with $95 \%$ ethanol $(\mathrm{w} / \mathrm{v}=1: 1.5)$ under room temperature for $24 \mathrm{~h}$. The residue was re-extracted twice with $80 \%$ (v/v) ethanol. Ethanol extracts were mixed together and evaporated to $3 \mathrm{~L}$ in a rotatory evaporator and extracted with $1.5 \mathrm{~L}$ of petroleum ether three times to remove the lipid components and followed by $3 \mathrm{~L}$ of ethyl acetate extraction for 5 times. The ethyl acetate layer was evaporated in a rotatory evaporator at $35^{\circ} \mathrm{C}$ to produce a final extract of $150.50 \mathrm{~g}$ of the extract was dissolved in 100 $\mathrm{mL}$ water and the solution was added to a Sephadex LH-20 column ( $375 \mathrm{~mm} \times 45 \mathrm{~mm}$ i.d.) at a flow rate $10 \mathrm{~mL} / \mathrm{min}$ and eluted respectively with 40, 50, 60, 70, 80 and $100 \%$ methanol (v/v, in $0.02 \%$ formic acid, 2 bed volume (BV), each 1200 $\mathrm{mL}$ ). Each $0.5 \mathrm{BV}$ eluate was collected and monitored by HPLC. The elution was carried out with $12 \%$ acetonitrile (v/v) in $0.02 \%$ formic acid. The column temperature was $35^{\circ} \mathrm{C}$. The flow rate was $0.8 \mathrm{~mL} / \mathrm{min}$ and the injection volume was $5 \mu \mathrm{L}$. The eluates from $3^{\text {rd }}$ to $4^{\text {th }}$ fractions were mixed, evaporated (under reduced pressure) and lyophilized and then purified with a preparative HPLC system. The elution was carried out with $25 \%$ methanol (v/v) in $0.02 \%$ formic acid at the flow rate $10 \mathrm{~mL} / \mathrm{min}$ and the wavelength for detection was $280 \mathrm{~nm}$. The chromatography was repeated and the fractions at retention time $9 \mathrm{~min}$ were collected, evaporated (under reduced pressure) and lyophilized to obtain achromous solids $197 \mathrm{mg}$ of compound $\mathbf{1}$.

Synthesis and purification of eucomic acid 1,4-dimethyl ester: $30 \mathrm{mg}$ compound 1 was dissolved in $6 \mathrm{~mL}$ methanol and $720 \mu \mathrm{L}$ concentrated sulphuric acid was added and then sealed at $80^{\circ} \mathrm{C}$ for a $1 \mathrm{~h}$ reaction. After cooling, $6 \mathrm{~mL}$ of distilled water was added to the reaction mixture and extracted with the equivalent volume of diethyl ether 3 times. Diethyl ether extracts were mixed together, dried with anhydrous sodium sulfate, concentrated and then purified with a preparative
HPLC system. The elution was carried out with $45 \%$ methanol in $0.02 \%$ formic acid: the flow rate was $10 \mathrm{~mL} / \mathrm{min}$ at $25^{\circ} \mathrm{C}$ and the wavelength was $280 \mathrm{~nm}$. The fractions at retention time 20 min were collected, evaporated (under reduced pressure) and lyophilized to obtain compound 2.

Liquid chromatography-mass spectrometry (LC-MS) analysis of compound 1: The HPLC analysis was performed on a Mightysil RP-18 GP Aqua column $(250 \mathrm{~mm} \times 4.6 \mathrm{~mm}$ i.d., $5 \mu \mathrm{m}$ ). $20 \%$ methanol in $0.3 \%$ formic acid was employed as mobile phase $\mathrm{A}$ and $30 \%$ acetonitrile in $0.3 \%$ formic acid was employed as mobile phase B. The gradient procedure was 0-6 min with $0 \% \mathrm{~B}, 15-25$ min with $25-60 \% \mathrm{~B}, 25-30 \mathrm{~min}$ with $60-100 \%$ B, 30-40 min with $100 \%$ B and 40-42 min with $100-0 \% \mathrm{~B}$. The column temperature was $40{ }^{\circ} \mathrm{C}$ and detection was carried out at $280 \mathrm{~nm}$. The injection volume was $5 \mu \mathrm{L}$. The mass spectrometer used nitrogen gas at a temperature of $350{ }^{\circ} \mathrm{C}$, a flow rate of $10 \mathrm{~mL} / \mathrm{min}$, a nebulizer pressure of 50 psi and the scanning range was $m / z, 50-2000$ in positive mode.

NMR analysis of compound 1 and 2: Each $5 \mathrm{mg}$ of compound 1 and 2 were dissolved in $\mathrm{CD}_{3} \mathrm{SOCD}_{3}$ and $\mathrm{CD}_{3} \mathrm{COCD}_{3}$. TMS was the reference reagent. The ${ }^{1} \mathrm{H}$ NMR and ${ }^{13} \mathrm{C}$ NMR spectra, H-H homonuclear correlation spectroscopy (COSY), multi-key hydrocarbon relationship (HMBC) and heteronuclear multiple quantum relations (HMQC) were analyzed.

Sample preparation: Each $10 \mathrm{~g}$ of the hawthorn fruits, hawthorn jam, hawthorn soup and hawthorn jelly were ground into a cream with $95 \%$ ethanol. The cream slurry was transferred to a $50 \mathrm{~mL}$ volumetric flask using $95 \%$ ethanol and processed in an ultrasonic homogenizer for $10 \mathrm{~min} .10 \mathrm{~g}$ of the hawthorn juice was transferred to a $50 \mathrm{~mL}$ volumetric flask using $95 \%$ ethanol. $10 \mathrm{~mL}$ of supernatant was evaporated to dryness with a vacuum, dissolved in $15 \mathrm{~mL}$ sulphuric acidmethanol solution, sealed and then reacted and heated at $80{ }^{\circ} \mathrm{C}$ for $1 \mathrm{~h}$. After cooling, $15 \mathrm{~mL}$ distilled water was added to the reaction mixture and extracted with the $8 \mathrm{~mL}$ of dichloromethane 3 times. Dichloromethane extracts were mixed together to a constant volume of $25 \mathrm{~mL}$ after being dried by anhydrous sodium sulfate. The solution was filtered through a $0.45 \mu \mathrm{m}$ membrane, a portion of the filtrate was directly used for the determination by GC-MS.

GC-MS analysis: Operating conditions for the GC were: the oven temperature was programmed at $60{ }^{\circ} \mathrm{C}$ for $1 \mathrm{~min}$, ramped to $160{ }^{\circ} \mathrm{C}$ at $20{ }^{\circ} \mathrm{C} / \mathrm{min}$, held for $1 \mathrm{~min}$ and then to $250{ }^{\circ} \mathrm{C}$ at $20^{\circ} \mathrm{C} / \mathrm{min}$ and held for $3 \mathrm{~min}$. The injection port temperature was $250{ }^{\circ} \mathrm{C}$, helium was used as carrier gas at a flow rate of $1 \mathrm{~mL} / \mathrm{min}$. The split ratio was 20:1, the injection volume was $1 \mu \mathrm{L}$. The MS was operated in electron ionization (EI) mode at $70 \mathrm{eV}$ with a transfer line temperature of $250^{\circ} \mathrm{C}$, ion source $230{ }^{\circ} \mathrm{C}$, quadrupole temperature $150{ }^{\circ} \mathrm{C}$. The samples were analyzed qualitatively based on retention time of chromatography and mass spectra of reference substance with full scan mode (SCAN). The characterizing ions of selective ion monitoring (SIM) mode were $\mathrm{m} / \mathrm{z}=107$ and the external reference method was used in the quantitative analysis.

\section{RESULTS AND DISCUSSION}

Structural identification of eucomic acid and its esterified esters: Compound $\mathbf{1}$ was obtained by separation and purification from hawthorn according to the steps described 
in extraction and purification of eucomic acid. HPLC was used to analyze the purity of the chromatographic peak of compound 1. The maximum absorption wavelength was $278 \mathrm{~nm}$ in the ultraviolet spectra (UV) absorption spectrogram. As the mobile phase acidity increased, retention time decreased. This suggested that it might be one of organic acids. By LC-MS analysis, compound $\mathbf{1}$ showed molecular ion peak with $\mathrm{m} / \mathrm{z}$ $263[\mathrm{M}+\mathrm{Na}]^{+}$which is consistent with the eucomic acid. The ${ }^{1} \mathrm{H} \mathrm{NMR},{ }^{13} \mathrm{C}$ NMR analysis were as follows: NMR $\delta_{\mathrm{H}}(\mathrm{DMSO}-$ $\left.d_{6}\right)$ : 6.981 (2 H, d, $J=8$ Hz, H-2', H-6'), 6.620 (2 H, d, $J=8$ Hz, H-3', H-5'), 2.795 (1 H, d, J = 3.5 Hz, H-5b), 2.741 (1 H, $\mathrm{d}, J=3.5 \mathrm{~Hz}, \mathrm{H}-5 \mathrm{a}), 2.692(1 \mathrm{H}, \mathrm{d}, J=16 \mathrm{~Hz}, \mathrm{H}-3 \mathrm{~b}), 2.347$ (1 $\mathrm{H}, \mathrm{d}, J=16 \mathrm{~Hz}, \mathrm{H}-3 \mathrm{a})$. NMR $\delta_{\mathrm{C}}\left(\mathrm{DMSO}-d_{6}\right): 175.7(\mathrm{C}-4)$, 171.7 (C-1), 156.1 (C-4'), 131.5 (C-2', C-6'), 126.3 (C-1'), 114.7 (C-3', C-5'), 75.0 (C-2), 43.8 (C-5), 42.6 (C-3). These data and the 2D NMR analysis, including ${ }^{1} \mathrm{H}-{ }^{1} \mathrm{H}$ COSY, HMQC, HMBC and NOESY spectra, were in accordance with those reported in the literature ${ }^{4,5}$. Therefore, compound $\mathbf{1}$ was identified as eucomic acid and was taken as the quantification standard in this experiment.

Eucomic acid methyl ester were prepared according to the steps described in synthesis and purification of eucomic acid dimethyl ester and purified by preparative HPLC. Total ion chromatogram (TIC) and EI spectra were analysed by GCMS. As shown in Fig. 2, retention time was 12 min, hydroxybenzyl ion peaks $\mathrm{m} / \mathrm{z} 107$ was the strongest and dehydrated
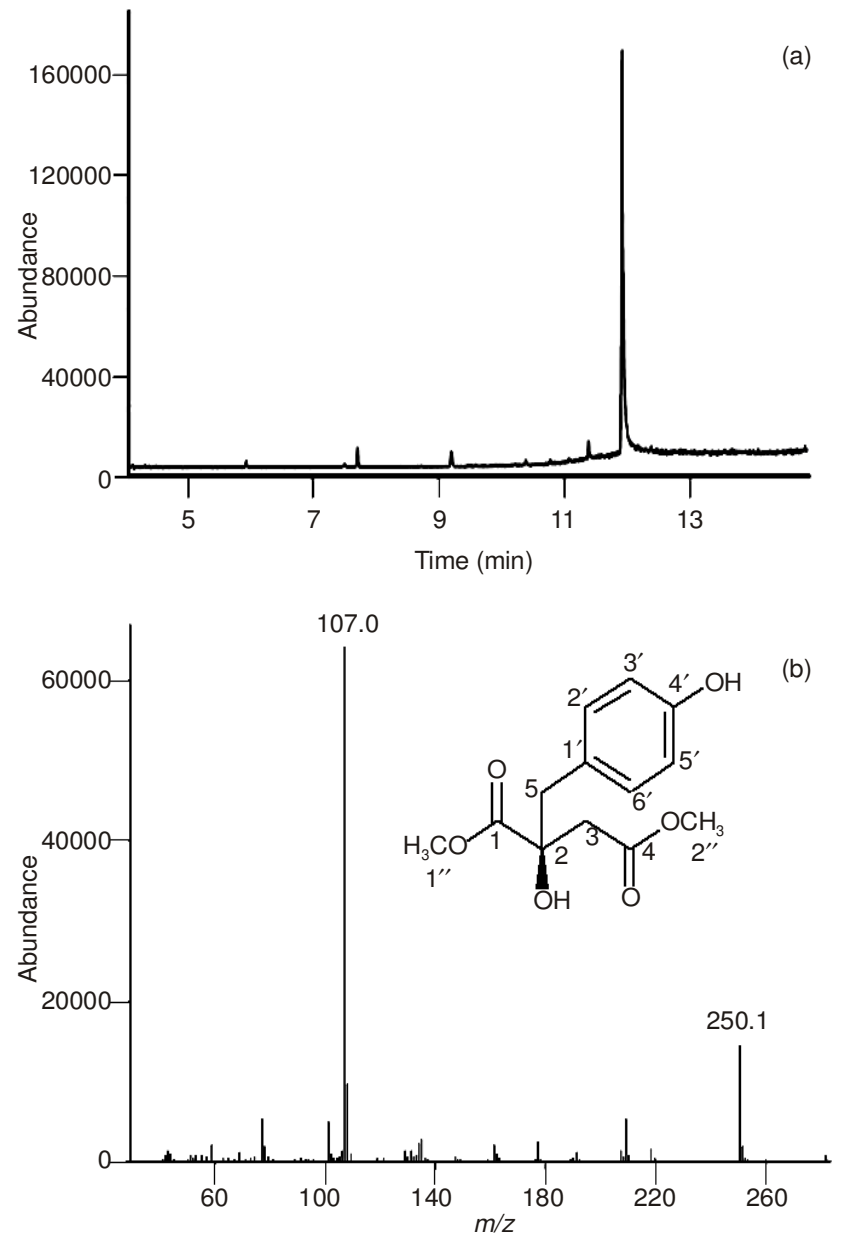

Fig. 2. Total ion chromatogram (a) and mass spectra (b) of eucomic acid 1,4-dimethyl ester ion peaks $m / z=250$ was also obvious. The ${ }^{1} \mathrm{H}$ NMR, ${ }^{13} \mathrm{C} \mathrm{NMR}$ analysis were observed: NMR $\delta_{\mathrm{H}}\left(\mathrm{CD}_{3} \mathrm{COCD}_{3}\right): 7.035(2 \mathrm{H}$, d, $\left.J=8 \mathrm{~Hz}, \mathrm{H}-2^{\prime}, \mathrm{H}-6^{\prime}\right), 6.74$ (2 H, d, $\left.J=8 \mathrm{~Hz}, \mathrm{H}-3^{\prime}, \mathrm{H}-5^{\prime}\right)$, 3.68 ( $\left.3 \mathrm{H}, \mathrm{d}, J=52 \mathrm{~Hz}, \mathrm{H}-2^{\prime \prime}\right), 3.59$ (3 H, d, $\left.J=52 \mathrm{~Hz}, \mathrm{H}-1 "\right)$, 2.95 ( $1 \mathrm{H}, \mathrm{d}, J=14 \mathrm{~Hz}, \mathrm{H}-5 \mathrm{a}), 2.93$ (1 H, d, $J=11 \mathrm{~Hz}, \mathrm{H}-5 \mathrm{~b})$, 2.85 (1 H, d, J=14 Hz, H-3b), 2.62 (1 H, d, $J=16 \mathrm{~Hz}, \mathrm{H}-3 \mathrm{a})$. NMR $\delta_{\mathrm{C}}\left(\mathrm{CD}_{3} \mathrm{COCD}_{3}\right): 170.51(\mathrm{C}-1), 156.35\left(\mathrm{C}-4^{\prime}\right), 131.32$ (C-2', C-6'), 126.15 (C-1'), 114.7 (C-3', C-5'), 75.8 (C-2), 51.67 (C-2"), 50.89 (C-1"), 44.3 (C-5), 42.6 (C-3). The chemical structure of compound 2 was confirmed by ${ }^{1} \mathrm{H}$ NMR, ${ }^{13} \mathrm{C}$ NMR, ${ }^{1} \mathrm{H}-{ }^{1} \mathrm{H}$ COSY, HMQC, HMBC, NOESY spectra and mass spectrometry. Compound 2 was identified as eucomic acid 1,4dimethyl ester ((R)-2-(4'-hydroxybenzyl)-malic acid 1,4dimethyl ester).

Optimization of the condition of eucomic acid esterification: In order to examine the influence of esterification in hawthorn fruit juice, different amount of sulfuric acid were mixed with methanol according to the method used in sample preparation, which was followed by the quantification method of eucomic acid methyl ester described in GC-MS analysis. Fig. 3 showed that the esterification product was significantly increased when the amount of sulfuric acid increased. The esterification product was saturated at $12 \mathrm{~mL}$ sulfuric acid per $100 \mathrm{~mL}$ methanol and was stable when increasing the sulfuric acid content. Therefore, we used the reaction solution which had a sulfuric acid to methanol ratio equal to $12: 100$.

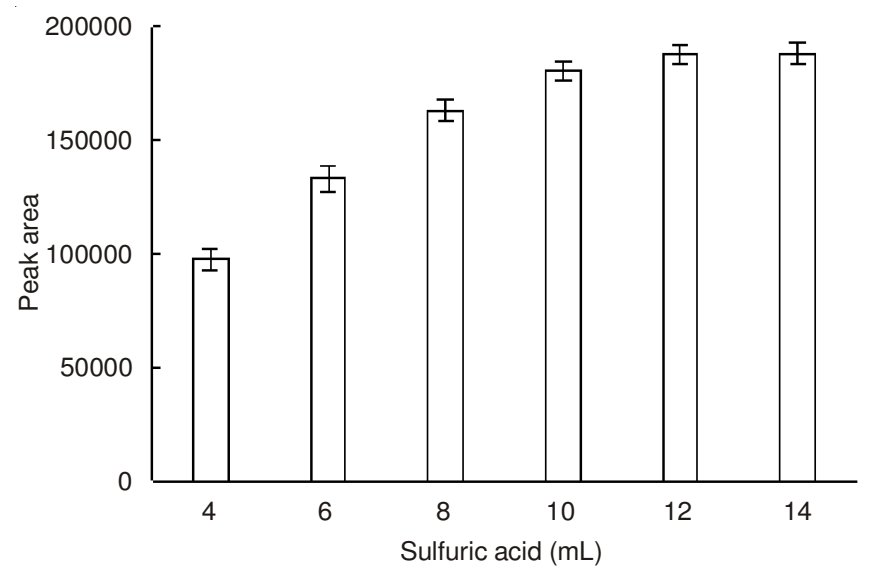

Fig. 3. Effect of sulfuric acid on esterification

To examine the effect of temperature on esterification, reaction temperature was respectively set at 20, 40, 60, 80 and $100{ }^{\circ} \mathrm{C}$ according to the steps described in sample preparation. Sample analysis is described in GC-MS analysis and the results are shown in Fig. 4. The esterification reaction was weak at $20{ }^{\circ} \mathrm{C}$. As the temperature increased, the reaction rate accelerated. The highest esterification product was obtained at $80^{\circ} \mathrm{C}$, with little increase in esterification product at $100{ }^{\circ} \mathrm{C}$. Therefore, this study was performed at an $80{ }^{\circ} \mathrm{C}$ water bath.

To observe the effect of time on esterification, different reaction times were used according to the steps described in sample preparation and the analytical method in GC-MS analysis and the results are shown in Fig. 5. We observed that the esterification product was optimized when reaction time was $1 \mathrm{~h}$. No significant improvement was observed when increasing reaction time. Thereby, $1 \mathrm{~h}$ was used as the reaction time. 


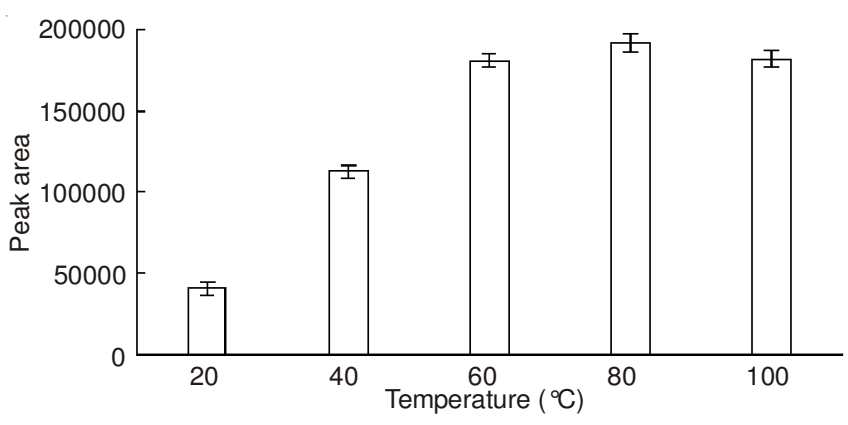

Fig. 4. Effect of temperature on the esterification

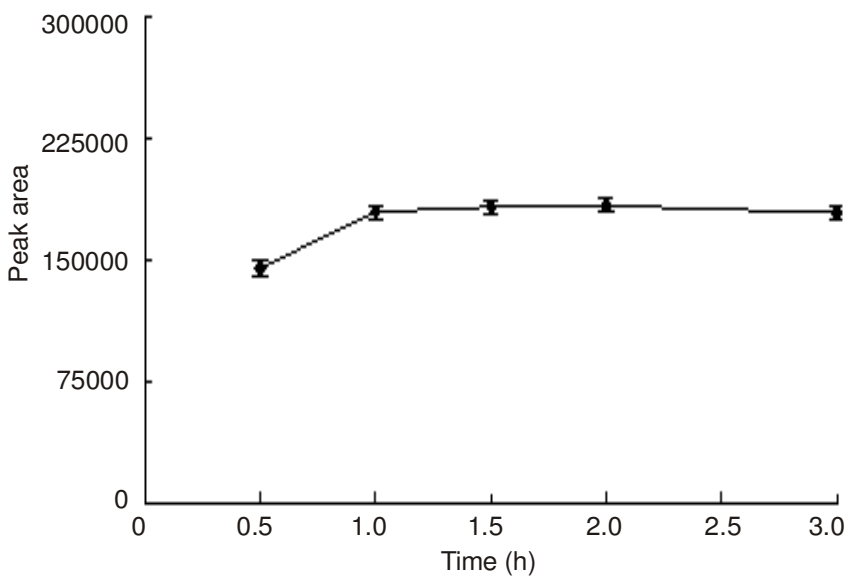

Fig. 5. Effect of reaction time on the esterification

Selection of capillary chromatographic column: KB-1 (30 $\mathrm{m} \times 0.25 \mathrm{~mm}$, i.d., $0.25 \mu \mathrm{m}$, Kromat), HP-5MS and HPINNOWAX ( $30 \mathrm{~m} \times 0.25 \mathrm{~mm}$, i.d., $0.25 \mu \mathrm{m}$, Agilent) capillary chromatographic column were used to assess the isolation effect. After adjusting GC conditions many times, no esterification products of eucomic acid were monitored with KB-1. It may be due to the fact that the retention time of the eucomic acid peak was too short for non-polar column KB-1. Even when the initial column temperature was at $40^{\circ} \mathrm{C}$ for $10 \mathrm{~min}$, the peak also did not separate well with the solvent peak. The esterification product of eucomic acid could be monitored by both HP-5MS and HP-INNOWAX. Although in HP-INNOWAX, it took a long time at a high temperature program (close to the column temperature limit) and the peak was obviously smeared. Therefore, we chose HP-5MS in analyzing the samples.

GC-MS analysis of eucomic acid 1,4-dimethyl ester: Compared with the European hawthorn, one of the obvious features of Chinese hawthorn fruit was that it contains large amount of organic acids, such as citric, malic, oxalic, succinic acids ${ }^{16,17}$. The methyl ester derivatives of these organic acids can be washed out and separated in a short time under the chromatographic condition described in GC-MS analysis. Fig. 6 shows there is no obvious interference components near eucomic acid 1,4-dimethyl ester. The methyl ester derivations of other organic acids such as 4-hydroxy-pentanoic acid, malic acid, citric acid and isocitrate can also be well separated. We used the fragment ions $\mathrm{m} / \mathrm{z}, 107$ for monitoring and quantitative analysis under selected ion monitoring (SIM). The analysis method had higher sensitivity, decreased other interference and other methyl ester derivates did not give detection signals.

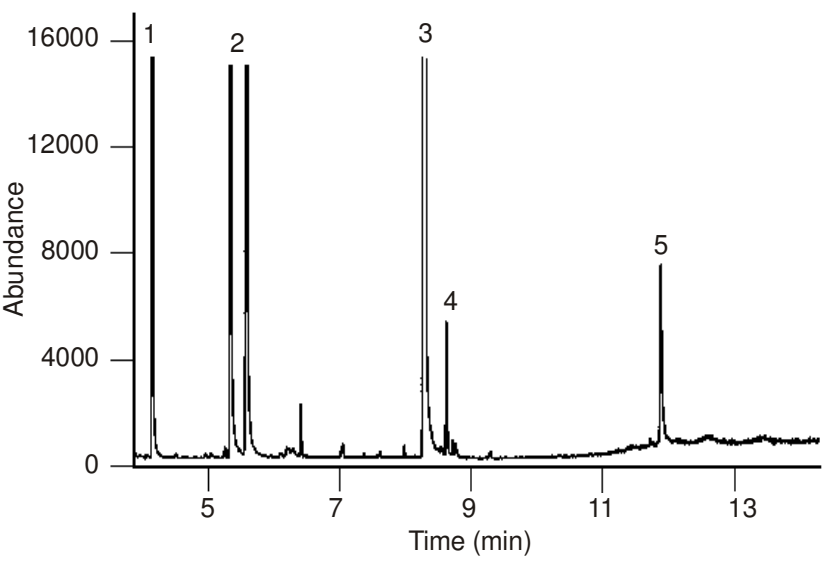

Fig. 6. GC-MS total ion current (TIC) chromatogram of a hawthorn sample after methyl esterification; $1=4$-oxo-pentanoic acid; $2=$ malic acid; 3 = citric acid; $4=$ isocitric acid; $5=$ eucomic acid

Linearity, recovery and precision: Eucomic acid was prepared at the concentration of $2 \mathrm{mg} / \mathrm{mL}$ in methanol. The esterification, extraction and analysis were performed according to sample preparation and GC-MS analysis. The developed GC-MS method showed excellent linearity $\left(r^{2}=0.9997\right)$ in the 4-1000 $\mu \mathrm{g}$ range, with a concentration $2-500 \mu \mathrm{g} / \mathrm{g}$ in sample. The detection limits (for $\mathrm{S} / \mathrm{N}=3$ ) was $0.35 \mu \mathrm{g} / \mathrm{g}$. The average recovery rate was determinate by five replication at three levels of 20,200,400 $\mu \mathrm{g} / \mathrm{g}$, respectively. The results of average recovery and precision are shown in Table-1.

TABLE-1

AVERAGE RECOVERY RATE AND RELATIVE STANDARD DEVIATION $(n=5)$ OF EUCOMIC ACID

\begin{tabular}{cccc}
\hline Added $(\mu \mathrm{g} / \mathrm{g})$ & Found $(\mu \mathrm{g} / \mathrm{g})$ & Recovery $(\%)$ & RSD \\
\hline 20 & 17 & 87 & 5.6 \\
200 & 180 & 90 & 3.1 \\
400 & 410 & 102 & 4.5 \\
\hline
\end{tabular}

Quantification of hawthorn products: The established GC-MS method was used to determine the content of eucomic acid in hawthorn fruit and products, which is given in Table- 2 . The content of eucomic acid in hawthorn products was significantly lower compared to hawthorn fruit. It is known that eucomic acid is chemically stable and is not expected to be lost in a significant amount during processing besides thermal volatilization. The low content of eucomic acid in this study indicated that the content of hawthorn fruit is actually not high in these products. Research relevant to eucomic acid should continue to identify the characteristic fragrance of hawthorn fruit. We expect our analytical method can be applied as a method in monitoring the quality of hawthorn products for manufacturers and market regulators.

TABLE-2

CONTENT OF EUCOMIC ACID IN HAWTHORN FRUIT AND PRODUCTS

\begin{tabular}{ccccccc}
\hline & Fruits & Juice I & Juice II & Jam & Soup & Jelly \\
\hline $\begin{array}{c}\text { Content } \\
(\mu \mathrm{g} / \mathrm{g})\end{array}$ & 255 & 15.4 & 17.9 & 7.2 & 5.1 & 7.8 \\
\hline
\end{tabular}




\section{ACKNOWLEDGEMENTS}

This project was financially supported by the National Natural Science Foundation of China (31071494), Natural Science Foundation of Hebei Province (C2011204093) and Project of Human Resources and Social Security of Hebei Province 2010-195.

\section{REFERENCES}

1. H.H.S. Fong and J.L.J. Bauman, Cardiovasc. Nurs., 16, 1 (2002)

2. J.M. Rigelsky and B.V.H. Sweet, Am. J. Health Syst. Pharm., 59, 417 (2002)

3. D.S. Ding and B.X. Li, Flavour Fragrance Cosmet., 57, 4 (1999).

4. W. Heller and C. Tamm, Helv. Chim. Acta, 57, 1766 (1974).

5. T. Koizumi, Y. Isogai, S. Nomoto, K. Shudo and T. Okamoto, Phytochemistry, 15, 342 (1976).

6. M. Ishii, S. Uemoto, K. Fujieda, M. Nonaka, Y. Shoyama, Y. Miyahara and I. Nishioka, Phytochemistry, 18, 1211 (1979).
7. J.Q. Jiang, W.C. Ye, Z. Chen, F.C. Lou and Z.D. Min, J. Chin. Pharm. Sci., 11, 1 (2002)

8. A. Mun'Im, O. Negishi and T. Ozawa, Biosci. Biotechnol. Biochem., 67, 410 (2003).

9. F.C. Stintzing and R. Carle, Mol. Nutr. Food Res., 49, 175 (2005).

10. J.Q. Jiang, Y.F. Li, Z. Chen, Z.D. Min and F.C. Lou, Steroids, 71, 1073 (2006).

11. C.E. Tovar-Gijón, B. Hernández-Carlos, E. Burgueño-Tapia, E. CedilloPortugal and P.J. Joseph-Nathan, Mol. Struct., 783, 96 (2006).

12. G. Ginestra, M.L. Parker, R.N. Bennett, J. Robertson, G. Mandalari, A. Narbad, R.B. Lo Curto, G. Bisignano, C.B. Faulds and K.W.J. Waldron, Agric. Food Chem., 57, 10323 (2009).

13. J.Y. Sun, X.R. Liu, H.Y. Wu and K. Liu, Food Drug., 13, 441 (2011).

14. M. Okada, S. Park, T. Koshizawa and M. Ueda, Tetrahedron, 65, 2136 (2009).

15. C. Simmler, C. Antheaume, P. André, F. Bonté and A. Lobstein, J. Nat. Prod., 74, 949 (2011).

16. G.Y. Gao, Y.X. Feng and X.Q. Qin, Acta Pharmacol. Sin., 30, 138 (1995).

17. X.Y. Shi and Y.H. Ma, Food Sci., 29, 297 (2008). 